Ambient Science, 2016: Vol. 03(Sp1); 40-44

DOI:10.21276/ambi.2016.03.sp1.ra05

ambient

SCIENCE

Vol. 3(Sp1):40-44

Year 2016

RESEARCH ARTICLE

\title{
Power of Stress Management Skill Training on Levels of Depression, Anxiety and Stress in Patients Suffering from Type-2 Diabetes
}

\section{Shirin Mirzaei ${ }^{1 *}$, Vahide Dahaghin ${ }^{2}$, Sedighe Gozal $^{3}$, Rahele Azhdari ${ }^{3}$, Neda Ahmadi ${ }^{4}$}

'Department of Public Psychology, Half of Allameh Tabatabai University, Tehran Province, Iran

${ }^{2}$ Department of Clinical Psychology, Science and Medicine, Tehran University, Iran

${ }^{3}$ Department of Psychometric, Center of Tehran branch, Azad University, Iran

${ }^{4}$ Department of Exceptional Children Psychology, Azad University, Center of Tehran Branch, Iran

Study Area: Imam Khomeini Hospital, Tehran, Iran

Coordinate: $35^{\circ} 41^{\prime \prime} 46^{\prime} \mathrm{N} ; 51^{\circ} 25^{\prime \prime} 23^{\prime} \mathrm{E}$

Key words: Depression, Anxiety, Stress, Skill training

\section{Abstract}

Stress management skill training was always been known toi be benif icial on depression, anxiety and stress. We applied the same in patients suffering from type-2 diabetes through quasi-experimental method following the pre and post test design method with a control group. Twenty diabetic patients (10 females, 10 males) were selected and randomly divide into two groups; test and control ( $\mathrm{n}=12$ each) Levels of depression, anxiety and stress were measured by using depression, anxiety and stress questionnaire (Dass-21) in the pre-test phases which was followed by the stress reduction skill training conducted in 10 different sessions only for the test group. At the end of re-interventions, levels of depression, anxiety and stress of patients were measured and the data were analyzed by using analysis of variance. Significant differences between levels of depression, anxiety and stress in two groups were found which was finally reduced in the test group by the stress management skill training. Conclusively, stress management skill could be an appropriate treatment method for improving mood disorders, in patients suffering from type-2 diabetes.

Depression in such patients reduces their desire, motivation and confidence to perform self-care activities (Li et al., 2008). In in-health clinical psychology, during the treatment of type-2 diabetic patients, psychological adjustment, strategies to cope with the disease and to adhere to the treatment program to improve it are main areas to concentrate (Tak-Ying et al., 2003). In addition to the physical complications, stress caused by diabetes has some undesirable psychological complications which make diff icult the proper treatment and control diabetes. Thus, identification of psychological problems of such patients, removing or reducing them and providing training to improve their quality of life, constitutes an important part of a comprehensive treatment of diabetes (Engum, 2007). Stress management training can be beneficial in reducing anxiety and depression and in increasing strategies to cope with stress and it can serve as a solution to better control the disease and to reduce and prevent physical, psychosocial and social problems and complications associated with diabetes (Martinez, 2005).

Stress management is a set of techniques and methods used to reduce the stress suffered by people or to increase their ability to cope with daily stress (Shapiro et al., 2005). generalized depression and anxiety.

*Corresponding Author: mapbo@yahoo.com 
This method is known to be effective in many psychological disorders such as anxiety and depression, psychosomatic diseases and even in diseases such as cancer and multiple sclerosis (Saraf ino, 2002).

Considering physical and psychological problems of patients with diabetes and existence of evidences regarding the effectiveness of stress management training on depression, anxiety and stress in patients with diabetes and other chronic diseases, in the present study we attempted to find out the answer of " Do the stress management skill effective in the treatment of depression, anxiety and stress in patients with diabetes?" in order to determine the effectiveness of stress management skill on depression, anxiety and stress in these patients.

\section{Methodology:}

Among all the diabetic patients who referred to Imam Khomeini hospital in Tehran during the year 2015, twenty diabetic patients (10 females: 10 males) were selected and randomly divided into two groups; test and control with 10 individual in each. In this study we included the patients being diagnosed with type-2 diabetes, at least one year ago including the other characteristics as; except diabetes not suffering from any other chronic diseases, in between the age group of 20 and 55 years old, having no history of neurological and psychiatric diseases or hospitalization, no drug abuse, educated atleast up to school level. Further, participants were subjected to group therapy sessions. We excluded such diabetic patients who were absence over two sessions in the intervention sessions, reluctance to continue participation in intervention sessions.

Employed protocol: for this study, we used a quasiexperimental method with pre and post-test design with a control group. After determining the test and control groups, depression, anxiety, and stress related questionnaires (Dass-21) were served to the participants and scores were collected at pre-test phase. This study was conducted in the internal medicine ward of Imam Khomeini Hospital in Tehran, by two graduates of psychology familiar with intervention method following the basics of moral research standards, such as informed consent and keeping the secrets of participants. Questionnaires were filled out by the participants in three occasions, before the intervention (pre-test), after the intervention (post-test) and 2 months after the intervention (follow-up). Group treatments were administered in 8 sessions. Octoploid intervention sessions were conducted based on stress management skill protocol (Nyenwe et al., 2011) and they were administered once in a week, continuous for two hours among the participants of the test group. Participants in the control group received no intervention. Table 1 represents a summary of executive guideline for mindfulness-based stress reduction program sessions.
Tableı. Protocol of stress management skill training sessions

\begin{tabular}{|c|c|}
\hline Sessions & Issue \\
\hline 1st & $\begin{array}{l}\text { Introducing group members to each other, getting to } \\
\text { know each other, introducing stress, stressors, stress } \\
\text { responses and awareness of the physical effects of stress }\end{array}$ \\
\hline 2nd & $\begin{array}{l}\text { Informing participants about the effects of stress and } \\
\text { understanding the importance of this awareness and } \\
\text { increasing awareness of physical responses related to } \\
\text { stressors }\end{array}$ \\
\hline 3rd & $\begin{array}{l}\text { Explaining relationship between thoughts, emotions } \\
\text { and physical feelings and offering several examples in } \\
\text { different situations }\end{array}$ \\
\hline $4^{\text {th }}$ & $\begin{array}{l}\text { Introducing and identification of common types of } \\
\text { negative thoughtsand cognitive distortions }\end{array}$ \\
\hline $5^{\text {th }}$ & $\begin{array}{l}\text { Challenging common negative thoughts and cognitive } \\
\text { distortions and replacing irrational thoughts with } \\
\text { rational thoughts }\end{array}$ \\
\hline 6th & $\begin{array}{l}\text { Training, practicing and implementation of effective } \\
\text { coping strategies }\end{array}$ \\
\hline $7_{\text {th }}$ & $\begin{array}{l}\text { Continuing training, practicing and implementation of } \\
\text { effective coping strategies }\end{array}$ \\
\hline 8th & $\begin{array}{l}\text { Training and discussion about anger management, } \\
\text { decisiveness, time management and recording daily } \\
\text { events }\end{array}$ \\
\hline 9th & $\begin{array}{l}\text { Training benefiting from problem solving skills in the } \\
\text { conflicts, discussing the skills of saying no, delegation } \\
\text { of authority }\end{array}$ \\
\hline 1oth & $\begin{array}{l}\text { Training the importance and benefits of social } \\
\text { protectionand over-viewing the program }\end{array}$ \\
\hline
\end{tabular}

\section{Research Tools:}

The following questionnaires were used for data collection.

Demographic questionnaire: this questionnaire was used to collect demographic data, included the basic information like- age, marital status, education, socioeconomic status, educational background and working experience. In addition, questions regarding system by which the patient manages his/her diabetes, the amount of received insulin, alcohol consumption, and smoking were also included.

Structured clinical interview (SCID): we followed the Structured Clinical Interview (SCID) forwarded by First et al. (1997). It is a tool for diagnosis, based on the fourth edition of the diagnostic, and statistical manual of mental disorders. It has two main versions:

1. SCID-I evaluates major psychiatric disorders (the first axis in DSM-IV). This form was translated and adapted by Sharifi et al. (2005). The interview is applicable and reliable in the diagnosis of mental disorders. For example, Zanarini (200o) conducted a study to evaluate diagnostic validity of evaluators which reported more than 70\% Kappa, for most of the diagnoses. As per Bakhtiari (200o), the clinical psychology experts and professors conf irmed the utility of this tool. Test-retest reliability, with a one-week interval, was 0.95 (Katon, 2008).

2- SCID-II evaluates personality disorders (the second axis in II DSM-IV). Bakhtiari (200o) quoted work of Kabir Nejad et al. (2009) translated and adapted this form. It is a 
semi-structured clinical interview which evaluates personality disorders and it was first of all adopted in the year 1997. The content adaptability was tested according to the opinions of experts and reliability was also conf irmed by trial and error method. Acceptable reliability and adaptability were reported for this tool in various studies (Pradhan et al., 2007). Content adaptability of translated version was approved by three psychology professors and its trial and error reliability, with one-week interval was 0.87 (Bakhtiari, 2000).

Depression, anxiety and stress questionnaire (DASS21): this questionnaire was prepared by Lovibond \& Loviband (1995) to measure the depression, anxiety, and stress. Also, the results of confirmatory factors analysis have confirmed the existence of three factors; depression, anxiety, and stress. Trial and error reliability coeff icients of the three subscales of the questionnaire, with an interval of two weeks, in a unit composed of 20 patients were reported between 0.71-0.81 percent. Also, its reliability and adaptability were studied on a number of subjects in the UK (Mehta \& Wolfsdorf, 2010) and trial and error reliability for depression, anxiety, and stress, were reported to be 0.80 , 0.76 and 0.77 respectively and Cronbach's alpha for depression, anxiety, and stress were 0.810 .74 and 0.78 respectively.

\section{Results:}

In our study, 20 patients with type-2 diabetes (10 persons in control group and 10 persons in test group) in the age group of 32-49 years were included. The mean age of patients in the test group was $42 \pm 5.32$ years whereas of the control group was $40 \pm 4 \cdot 56$ years.

Tablez. The frequency and percentage of frequency of demographic characteristics

\begin{tabular}{|c|c|c|c|c|}
\hline Variables & Group & & Frq $^{*}$ & $\%$ \\
\hline \multirow{4}{*}{$\begin{array}{l}\text { Marital } \\
\text { status }\end{array}$} & \multirow[t]{2}{*}{ Control } & Married & 9 & $91 / 7$ \\
\hline & & Single & 1 & $8 / 3$ \\
\hline & \multirow[t]{2}{*}{ Test } & Married & 9 & $91 / 7$ \\
\hline & & Single & 1 & $8 / 3$ \\
\hline \multirow[t]{4}{*}{$\begin{array}{l}\text { Level of } \\
\text { Education }\end{array}$} & \multirow[t]{2}{*}{ Control } & $\begin{array}{l}\text { Guidance school \& } \\
\text { high school education }\end{array}$ & 3 & 25 \\
\hline & & College education & 7 & 75 \\
\hline & \multirow[t]{2}{*}{ Test } & $\begin{array}{l}\text { Guidance school \& } \\
\text { high school education }\end{array}$ & 4 & $33 / 3$ \\
\hline & & College education & 6 & $66 / 7$ \\
\hline \multirow{6}{*}{$\begin{array}{l}\text { Level of } \\
\text { income }\end{array}$} & \multirow[t]{3}{*}{ Control } & Low & - & - \\
\hline & & Medium & 6 & 50 \\
\hline & & High & 4 & 50 \\
\hline & \multirow[t]{3}{*}{ Test } & Low & - & - \\
\hline & & Medium & 6 & $66 / 7$ \\
\hline & & High & 4 & $33 / 3$ \\
\hline \multirow{4}{*}{$\begin{array}{l}\text { Work } \\
\text { status }\end{array}$} & \multirow[t]{2}{*}{ Control } & Homemakers or retired & 4 & $33 / 3$ \\
\hline & & Working & 6 & $66 / 7$ \\
\hline & \multirow[t]{2}{*}{ Test } & Homemakers or retired & 6 & 50 \\
\hline & & Working & 4 & 50 \\
\hline
\end{tabular}

${ }^{*}$ Frequency; \%-percent
Table 2 shows the frequency and the percentage of frequency of demographic characteristics of patients with diabetes in the two groups.

Tablez. The mean and standard deviation of subject's depression, anxiety and stress scores

\begin{tabular}{|c|c|c|c|c|c|c|}
\hline \multirow[t]{3}{*}{ Components } & \multicolumn{3}{|c|}{ Test group $(\mathrm{N}=12)$} & \multicolumn{3}{|c|}{ Control group $(\mathrm{N}=12)$} \\
\hline & \multirow{2}{*}{$\begin{array}{l}\text { Follow } \\
\text { up }\end{array}$} & \multirow{2}{*}{$\begin{array}{l}\text { Post } \\
\text {-test }\end{array}$} & \multirow{2}{*}{$\begin{array}{l}\text { Pre } \\
\text {-test }\end{array}$} & \multicolumn{2}{|c|}{ Follow Post } & \multirow{2}{*}{$\begin{array}{l}\text { Pre } \\
\text {-test }\end{array}$} \\
\hline & & & & up & -test & \\
\hline \multirow[t]{2}{*}{ Depression } & $17 \cdot 33^{ \pm}$ & $14.91 \pm$ & $0.91 \pm$ & $21.16 \pm$ & $21 \pm$ & $21.4^{ \pm}$ \\
\hline & 2.83 & 1.92 & 2.83 & 1.58 & 1.41 & 1.08 \\
\hline \multirow[t]{2}{*}{ Anxiety } & $12.33 \pm$ & $11.83 \pm$ & $0.08 \pm$ & $14 \cdot 33^{ \pm}$ & $14.41 \pm$ & $15 \cdot 33 \pm$ \\
\hline & 1.47 & 1.40 & 1.72 & 1.30 & 1.29 & 1.37 \\
\hline \multirow[t]{2}{*}{ Stress } & $23.58 \pm$ & $16.25 \pm$ & $0.33 \pm$ & $23 \cdot 58 \pm$ & $23.91 \pm$ & $24.25 \pm$ \\
\hline & 0.90 & 1.71 & 2.18 & 0.90 & 0.90 & 0.62 \\
\hline
\end{tabular}

In our study, the mean scores of depression, anxiety, stress in the test group after the intervention and follow-up have significantly changed in comparison to the measurement at the base line (pre-intervention phase); while the means of control group have not significantly changed while comparing the three phases (Table 3 ).

Table4. Summary results of analysis of covariance with repeated measures to determine effectiveness of mindfulness-based stress reduction therapy

\begin{tabular}{lllllll}
\hline & SS & df & MS & F-Ration & SL & ES \\
\hline Depression & 9.375 & 1 & 9.375 & 7.924 & 0.01 & 0.265 \\
Anxiety & 100.042 & 1 & 100.042 & 78.839 & 0.0001 & 0.782 \\
Stress & 47.227 & 1 & 47.227 & 17.362 & 0.0001 & 0.441 \\
\hline
\end{tabular}

* Abbreviations: SS-sum of squares; df-degree of freedom,

MS-Mean Square, SL-Significance level; ES- Eta-squard

Reviewing the results of $\mathrm{M}$-box test, regarding the components of depression ( $\mathrm{F}=2.702, \mathrm{P}<0.05)$, anxiety $(\mathrm{F}=$ 2.091, $\mathrm{P}<0.05)$, and stress $(\mathrm{F}=5.096, \mathrm{P}<0.05)$ showed that observed covariance matrix of dependent variables is equal among different groups. Further by applying an analysis of covariance test with repeated measures, we examined the effectiveness of stress management skill training on depression, anxiety, and stress in patients with diabetes and the results are summarized in Table-4. The results of analysis of variance repeated measures indicated that mindfulness interventions had created a significant difference on components of depression, anxiety, and stress among two groups at three evaluation sessions.

\section{Discussion :}

Previous studies have reported that people with diabetes faces an extreme reduction in -and even lack of- freshness and vitality, terrible fatigue, depression, quick anger and tension and stress complications (Tanaka et al., 2007). Since diabetes affects patients' perception and their satisfaction towards their own health and decreases their physical, mental and social well-being; thus it is essential to consider the importance of the psychological aspect of such patients. Our results revealed that stress management skill training through using group method 
reduce depression, anxiety, and stress in patients with diabetes. This result is consistent with previous studies which showed that such applied training can be an effective psychological-social intervention in the improvement of patients' mood disorders (Oliveira et al., 2009). The results of a research conducted by Carlson \& Speca (2011) showed that stress management skill training -while reduces stress- can signif icantly increase patients' mental clarity and their mental health. These researchers concluded that stress management skill training plays a major role in the recovery signs and bring positive results, following the participation of the subject in the treatment program (Kautzky-Willer \& Handisurya, 2009).

Since people with diabetes struggle with the complications of the disease for a long time which imposes severe stress on them. Finally, the patients leads to the formation of dysfunctional coping responses, including social isolation and negative self-criticism.

Stress management skill training with group approach creates tranquility through relaxation exercises and by enhancing self-awareness and self-acceptance abilities in patients (Nomura et al., 2000). Meeting similar people is a source of comfort and reassurance for patients which can urge them to learn coping techniques to overcome the problem and to solve it. When patients with high blood sugar communicate with each other and sympathize and discuss their problems and experiences; it will create a supportive environment to transfer knowledge and awareness (Peyrot et al., 1999). In general, factors of group therapy such as: releasing of excitement, sense of acceptance, philanthropy, public approval, sympathy, simulation, imitation, insight, interaction, learning, reality testing, transfer, considering universal and many other factors would lead to improvement of coping ability to adapt, creating a sense of hope and better response to the treatment and as a result they will reduce the anxiety and will increase the quality of life (Weijman et al., 2005). This study has special limitations. i.e., the small sample size. Although the number of subjects (participants) didn't decline along the study; but the small sample size is a limitation which prevents for obtaining an accurate estimation of the degree of effectiveness of any program. The second limitation was related to applying self-report measures. These tools have some inherent problems (such as measurement error, lack of introspection, etc.). The third limitation was a lack of control on underlying and personal factors. It is due to some underlying factors the participants have overestimated the effectiveness of the program. Another possibility was that people have overestimated the effectiveness of the program, due to some personal desires, optimism and such factors. It is thus suggested to conduct some pseudo treatment programs (placebo programs) on the controller in future programs to control the effect of expectations. Also, it is suggested to use larger samples to achieve the true degree of effectiveness of the program. This study was conducted on patients in Imam Khomeini Hospital, located in Tehran. It is suggested that researchers conduct stress management skill training with group approach in similar patients in other hospitals in order to develop the findings of this study.

\section{Acknowledgements:}

The researcher would like to appreciate all of Imam Khomeini Hospital staff and those patients who helped the researchers in the culmination of this study.

\section{References:}

ADA (American Diabetes Association). (2005): National standards for diabetes self-management education. Diabetes Care, 28(11): 72-79.

Boardman, J.D. \& Alexander, K.B. (2011): Stress trajectories, health behaviors, and the mental health of black and white young adults. Soc. Sci. Med., 72:1659-1666.

Brod, M., Kongso, J.H., Lessard, S. \& Christensen, T.L. (2009): Psychological insulin resistance: patient beliefs and implications for diabetes management. Qual.LifeRes., 18:23-32.

Carlson, L., \& Speca, M. (2011): Mindfulness - based cancer recovery. Oakland, CA: New Harbinger, 17-31.

Ellis, D.A., Frey, M., Naar-King, S., Templin, T., Cunningham, P. \& Cakan, N. (2005): Use of multisystemic therapy to improve regimen adherence among adolescents with type 1 diabetes in chronic poor metabolic control: a randomized controlled trial. Diabetes Care, 28 (7): 1604-1610.

Engum, A. (2007): The role of depression and anxiety in onset of diabetes in a large population-based study. J. Psychosom. Res., 62:31-8.

First, M.B., Spitzer, R.L., Gibbon, M. \& Williams, J.B.W. (1997): Structured clinical interview for DSM-IV axis I disorders (SCID-I), Clinician version. Washington, DC: American Psychiatric Association.

Katon, W.J. (2008): The comorbidity of diabetes mellitus and depression. Am.J.Med., 21 (11 Suppl. 2):S8-S15

Kautzky-Willer, A. \& Handisurya, A. (2009): Metabolic diseases and associated complications: sex and gender matter! Eur. J. Clin. Invest., 39:631-648.

Li, C., Barker, L., Ford, E.S., Zhang, X., Strine, T.W. \& Mokdad, A.H. (2008): Diabetes and anxiety in US adults: findings from the 2006 Behavioral Risk Factor Surveillance System. Diabet. Med., 25:878-881.

Lovibond, S.H. \& Lovibond, P.F. (1995). Manual for the Depression Anxiety \& Stress Scales. (2nd Ed.) Sydney: Psychology Foundation.

Martinez, S. (2005): Stress management as an adjunct treatment in patients identified with coronary artery disease: a program design. Carlos Albizu University, Florida.

NCCAM (National Center for Complementary and Alternative Medicine) (2009): NCCAM Backgrounder: Mind-body medicine: an overview [article online].

Nomura, M., Fujimoto, K., Higashino, A., Denzumi, M., 


\section{RESEARCH ARTICLE}

Miyagawa, M., Miyajima, H., Nada, T., Kondo, Y., Tada, Y., Kawaquchi, R., Morishita, T., Saito, K., Ito, S. \& Nakaya, Y. (2000): Stress and coping behavior in patients with diabetes mellitus. Acta Diabetol., 37:61-64.

Nyenwe, E.A., Jerkins, T.W., Umpierrez, G.E. \& Kitabchi, A.E. (2011): Management of type 2 diabetes: evolving strategies for the treatment of patients with type 2 diabetes. Metab., 6o: 123.

O'Connor, P.J., Crain, A.L., Rush, W.A., Hanson, A.M., Fischer, L.R. \& Kluznik, J.C. (2009): Does diabetes double the risk of depression? Ann. Fam. Med., 7:328-335.

Oliveira, A.F., Valente, J.G., Leite Ida C., Schramm, J.M., Azevedo, A.S. \& Gadelha, A.M. (2009): Global burden of disease attributable to diabetes mellitus in Brazil. Cad Saude Publica, 25:1234-1244.

Peyrot, M., McMurry J.F., Jr. \& Kruger, D.F. (1999): A biopsychosocial model of glycemic control in diabetes: stress, coping and regimen adherence. J. Health Soc. Behav., 40:141-158.

Pradhan, E.K., Baumgarten, M., Langenberg, P., Handwerger, B., Gilpinm A.K., Magyari, T. \& Berman, B.M. (2007): Effect of Mindfulness-Based Stress Reduction in rheumatoid arthritis patients. Arthritis Rheum, 57:1134-1142.

Mehta, S.N. \& Wolfsdorf, J.I. (2010): Contemporary Management of patients with type 1 Diabetes. Endocrin. Metab. Clin., 39: 573-593.
Sarafino, E. (2002): Health psychology 4th edition. John Wileyand Sons.

Shahrjerdi, S.H., Shavandi, N., Golpayegani, M. \& SheikhHasani, R. (2010): Effects of strenuous and stamina exercises on blood glucose control, quality of life and mental health of women with type two diabetes mellitus. Iran. J. Diabetes Lipid Disorders, 9 (1):35-44.

Shapiro, S.L., Astin, J.A., Bishop, S.R. \& Cardova, M. (2005): Mindfullness-based stress reduction for health care professionals. Int. J. Stress Manag., 12:164-176.

Tak-Ying, S.A., Kwan, J.J. \& Wong, R.Y. (2003): Social stigma as a barrier to diabetes selfmanagement: implications for multilevel interventions. L. Clin. Nurs., 12:149-150.

Tanaka, T., Tsukube, S., lzawa, K., Okochi, M., Lim, T.K. \& Watanabe, S. (2007): Electrochemical detection of HbAic, a marker [correction of maker] for diabetes, using a flow immunoassay system. Biosens. Bioelectron., 22: 2051-2056.

Vares, Z., Zandi, M., Baghaei, P., Alavi, N.M., Ajorpaz, N.M. (2010): Study of quality of life and associated factors in diabetes mellitus patients of Kashan Diabet Center. Nur. Res., 5 (17):14-22.

Weijman, I., Ros, W.J., Rutten, G.E., Schaufeli, W.B., Schabracq, M.J. \& Winnubst, J.A. (2005): The role of work-related and personal factors in diabetes self-management. Patient Educ. Couns., 59:87-96. 